\title{
Analysis of Ground Deformation Caused by Subway Tunnel Excavation in Kunming
}

\author{
Ping $\mathrm{Wei}^{1 *}$, Liuchuang $\mathrm{Wei}^{2}$ \\ ${ }^{1}$ Faculty of Architectural Engineering, Kunming University, Yunnan Kunming 650214, China \\ ${ }^{2}$ Faculty of Mechanical and Electrical Engineering, Kunming University, Yunnan Kunming 650214, China
}

\begin{abstract}
Research at home and abroad shows that subway excavation often causes soil stress loss, resulting in settlement deformation and horizontal displacement of stratum. Therefore, combined with the special engineering geological conditions in Kunming area, the foundation deformation caused by subway excavation is studied, so as to provide an important foundation for proposing the protection measures of surrounding buildings and buried pipelines and promoting the construction of subway.
\end{abstract}

\section{Overview}

Subway is a kind of rail transit with large passenger capacity, fast and punctual, comfortable, safe and environmental protection. The business along the line improves the living space and convenience, improves the urban investment environment, and changes the distance pattern between cities; the convenient connection between subway and airport, bus station, taxi station, bicycle and other public transport means greatly shortens the distance between cities, and greatly improves the urban investment environment; the change of urban distance pattern makes people live in the suburbs And the life of working and shopping in the city center has become a reality. It brings value-added to the land along the line, and brings a kind of "subway economy" with unlimited business opportunities, so as to boost a district and increase the appreciation space of property. According to the original regional conditions, the land price increase ratio of Metro to surrounding areas can reach $5 \%-15 \%$; the farther the original area is from the city center, the worse the original traffic conditions are, the higher the land price promotion ratio is. Directly or indirectly promote employment, the city's subway construction itself will provide a lot of employment opportunities, rail transit derivative industry or promote the development of other industries will also bring some employment opportunities, so as to increase the demand for the whole talent, enhance the mobility of talent, and speed up the transformation speed of urban talent structure from point, belt to three-dimensional and diversified.

As a convenient means of transportation in the city, the subway is buried in a small depth and often passes through the CBD or the core business district. There are many surface buildings and underground facilities. The soil settlement and horizontal displacement caused by subway excavation have a greater impact on the surrounding environment. Ground deformation may lead to ground buildings incline, even crack, collapse, and destroy underground pipelines; horizontal displacement of strata can cause the displacement of underground pile foundation and the dislocation of pipeline and channel, which will lead to the decrease of bearing capacity of pile foundation and affect the normal use of pipelines and channels, or even destroy them.

\section{Analysis of ground settlement and deformation caused by tunnel excavation}

In order to evaluate the influence of tunnel excavation on surrounding buildings and buried pipelines, the deformation affected area caused by tunnel excavation is usually evaluated first, and the main characteristics and displacement of soil deformation in different influence areas are determined. Finally, according to the displacement of buildings and buried pipelines or the interaction between structure and soil, the safety and protection measures of buildings and buried pipelines are evaluated.

The ground settlement and deformation caused by tunnel excavation are closely related to the soil layer and overlying soil layer. According to the analysis and research at home and abroad, the soil deformation caused by tunnel can be divided into two stages, namely, the instantaneous soil settlement and deformation caused by excavation unloading in the process of excavation, and the long-term deformation increasing with time due to the consolidation and creep of cohesive soil layer in the later stage of construction. The main factors causing soil deformation. 


\subsection{Elastoplastic deformation of soil caused by excavation and unloading}

In the process of tunnel excavation, the face pressure is usually less than the in-situ water and soil pressure. Therefore, in the process of excavation, the soil will have elastic-plastic deformation due to unloading. Under the limit condition, the ground above the tunnel face will collapse due to the pressure of the tunnel face is too small or the pressure system failure.

\subsection{Soil deformation caused by over excavation or line deviation}

For the shield tunnel, the excavation section is $10-63 \mathrm{~mm}$ larger than the outer diameter of the shield barrel; at the same time, due to the deviation and correction of the line, unnecessary over excavation is often caused. Although the gap between the shield barrel and the soil will be filled with mud, the mud pressure is less than the weight of the overlying soil, resulting in the settlement and deformation of the soil layer.

\subsection{Gap between segment and soil}

The segment is generally assembled in the tail shield of the shield machine; with the advance of the shield machine, there is a gap of about $85-185 \mathrm{~mm}$ between the segment and the soil layer. Although the pressure grouting can stabilize the soil layer between the segment and the soil, sometimes the grouting pressure is too small or the slurry shrinkage deformation will cause the instantaneous settlement of the ground.

\subsection{Bending deformation of segment}

With the advance of shield machine, the soil support will transit from face pressure to lining segment. Under the action of soil and water pressure, the segment will bend and deform, which will lead to the settlement and deformation of soil.

\subsection{Consolidation and creep of cohesive soil}

For shield tunneling in cohesive soil, the average normal stress of soil is often reduced, resulting in negative pore water pressure. As the pore pressure dissipates with time, the soil around the tunnel will absorb water and soften, resulting in the decrease of strength and the increase of deformation. For soft soil, even long-term rheology will occur.

\subsection{Cause formation loss}

Because of the obstacles moving along with the advance of shield, the gap in the stratum can not be filled in time by grouting after the shield passing through, which causes the formation loss.

\section{Analysis of instantaneous settlement of soil caused by excavation unloading}

For the instantaneous settlement of soil caused by excavation unloading, a large number of foreign scholars show that the three-dimensional settlement tank can effectively obtain the transverse and longitudinal section settlement curve.

The lateral settlement curve is the settlement curve on the vertical plane perpendicular to the long axis of the tunnel. At present, it is generally believed that the lateral settlement curve can be approximately described by the inverse normal distribution curve or Gaussian distribution curve proposed by O'Reilly \& New (1983) (as shown in Fig. 2). The settlement curve mainly consists of the down curved groove section near the tunnel center line and the reverse arch section far away from the tunnel center line. The turning point between the two sections is the reverse bending point. It can be seen from Figure 3 that if the distance iy from the bending point to the tunnel center line and the volume $\mathrm{V}$ of the settlement tank are known, then the maximum settlement Wmax $=\mathrm{V} /$ (2.5iy) and the settlement of any point in the cross section can be calculated by the formula $\mathrm{w}=\mathrm{Wmax} \times \exp (-\mathrm{Y} 2 /(2 \times$ iy 2$))$, where $\mathrm{W}$ is the settlement of any point in the cross-section, and $\mathrm{Y}$ is the distance between the point and the tunnel centerline. In addition, through the settlement curve function, the calculation formulas of maximum camber curvature, maximum slope, maximum horizontal displacement and maximum tensile strain in Fig. 3 can be derived. It can be seen that the main parameters to describe the lateral settlement tank are the volume $\mathrm{V}$ and the width parameter iy. At present, according to the theoretical research and in-situ monitoring, scholars at home and abroad have proposed the volume and width parameters of settlement trough in different areas and different soils, such as Schmidt (1969), Peck (1969), Cording \& Hansmire (1975), Attawell (1977), O'Reilly \& New (1983), etc.

The longitudinal settlement curve along the center line of the tunnel. It is generally believed that the longitudinal settlement curve along the tunnel center line can be approximately described by the longitudinal cumulative normal distribution settlement curve proposed by Attewell \& Woodman (1982) (Fig. 4). Similarly, the longitudinal settlement curve includes the subsidence section behind the tunnel face and the reverse arch section in front of the tunnel face, and the reverse bending point is the tunnel face. In this curve, the maximum settlement Wmax is the same as the lateral settlement curve. The settlement of any point on the longitudinal settlement curve can be calculated by $\mathrm{w}=$ Wmax $\times \phi(-\mathrm{X} / \mathrm{IX})$, where $\phi()$ is the cumulative normal distribution function, $\phi(-1)=0.159, \phi(0)=0.5$ and $\phi(1)=0.841$. Therefore, the main parameters describing the longitudinal settlement curve are maximum settlement Wmax and channel length parameter IX. 
Based on the above horizontal and vertical settlement curves, the three-dimensional land settlement trough above the tunnel front can be accurately described by three parameters: settlement trough volume $\mathrm{V}$, trough width parameter iy and trough length parameter IX. In engineering practice, it can be reasonably assumed that (Hanmiell, 1975) and (Armiix, 1975) can be applied to the engineering practice. Therefore, the threedimensional settlement tank can be further simplified as a distribution function of two parameters (Volume V, width and length I).

The method of land subsidence expressed by the above inverse normal distribution and cumulative distribution function is simple in calculation, but lacks clear theoretical basis. Loganathan (2000), Ran (2004), Ong (2007) and other scholars studied the soil displacement caused by tunnel excavation through centrifuge test. Sagaseta (1987), Verrujit \& Booker (1996), loganathan \& Poulos (1998), Park (2005) and Osman (2006) proposed analytical methods for predicting soil displacement caused by tunnel excavation for different tunnel deformation forms. However, most of these methods are based on homogeneous linear elastic soil, and can not reflect the influence of time effect. There are many reports on the field measurement of soil displacement caused by tunnel excavation, but there are relatively few reports on the field measurement after tunnel excavation (O'Reilly et al., 1991; Zhang et al., 2004).

In China, Dr. Sun Qing's thesis (2011) of Tongji University concluded that the long-term and instantaneous displacement of soil mass caused by tunnel excavation can be calculated by using the Mohr Coulomb model of non associated flow criterion through the shrinkage theory of cylindrical and spherical holes under drained and undrained conditions. Based on the source sink theory proposed by sagaseta and the ground deformation model proposed by Park (2004) to describe the boundary conditions of tunnel displacement, the displacement field of cylindrical hole shrinkage problem under drainage condition is modified, and a semi infinite space displacement solution more in line with the actual situation is obtained, that is, the long-term displacement solution of surrounding soil caused by tunnel excavation. For the instantaneous displacement of surrounding soil caused by tunnel excavation, the correction of Loganathan \& Poulos (1998) has proved to be in good agreement with the experimental and measured data, so the formula proposed by Loganathan \& Poulos (1998) can be directly used for the instantaneous soil displacement caused by tunnel excavation.

In addition, in the temporal and spatial distribution model of surface settlement caused by underground excavation of subway, Zhang Bo (2014) took the analysis of surface settlement caused by underground excavation of a subway tunnel in Beijing as an example to study the distribution law and time history distribution law of surface settlement. On the basis of a large number of measured data, the regression analysis of surface subsidence distribution is carried out based on peck formula, and the Gauss curve which envelops the measured data to the greatest extent is obtained through correction, and the range of surface settlement is obtained; based on logistic function model, the regression analysis of surface settlement changes from time to time is carried out, and the time history distribution rule of surface settlement and the time history distribution rule of settlement velocity are obtained Law. The space-time prediction curve of surface settlement obtained by this method is closely related to the soil properties and construction methods of the tunnel.

Li Zhen (2016) Master's thesis takes the bench method construction of the east section of Kunming Metro Line 3 as an example, and studies the surface settlement. The results show that: during the construction process of the shallow buried and subsurface excavation method of the east section of Kunming Metro Line 3, the ground settlement caused by the upper bench excavation accounts for about $55 \%$ of the total surface settlement; the ground settlement of Kunming Metro Line 3 is about $55 \%$ During the construction of metro tunnel in the east section of railway line 3 , the larger the thickness of tunnel cover soil, the smaller the surface settlement, and the settlement presents an inverse proportional relationship with the thickness of tunnel cover soil; the larger stage of settlement and settlement rate caused by shield construction occurs in the settlement stage before the shield machine passes through the construction operation and the settlement stage of the gap at the shield tail These two stages are most necessary. When the bench method is used to excavate the upper bench, it is the stage with the largest amount of land subsidence, and it is the stage to focus on monitoring and measuring. The ratio of the surface settlement generated by the upper bench excavation construction to the total surface settlement generated by the construction is more than $60 \%$. The overburden thickness of the tunnel in the east section of Kunming Metro Line 3 is in direct proportion to the influence of tunnel excavation on its surface. The surface settlement law of shield construction can be roughly divided into three stages: when the shield machine self excavation working face is close to the observation point until the excavation working face is located between the observation points, the surface settlement occurs at the excavation working face; when the shield tail of the shield machine leaves the monitoring measurement point, the surface settlement will occur (the surface settlement generated in this stage is the largest); when the shield tail of the shield machine is close to the observation point, the surface settlement occurs After passing through the measuring points, the surface subsidence rate is faster in this stage.

\section{Conclusion}

From the current research results, we can see that the mechanism and calculation method of soil instantaneous displacement caused by tunnel excavation are not yet mature, so it is necessary to continue to study and discuss. Moreover, the long-term interaction between tunnel and soil in soft clay needs to be further studied. 


\section{Acknowledgements}

This paper has been supported with the science \& technology plan item found from Yunnan Provincial Department of Science \& Technology-university joint fund surface item (2018FH001-048) and the scientific research item found from Yunnan Provincial Department of Education (2020J0515).

\section{References}

1. YEATES, J., (1985) The response of buried pipelines to ground movements caused by tunnelling in soil. Ground Movements and Structures. Cardiff 1984. Ground Movements and Structures.

2. Mair, RJ., Gunn MJ., and O'reilly, M.P., (1982) Ground movement around shallow tunnels in soft clay. Tunnels \& Tunnelling.

3. Peck R B., (1969) Deep excavations and tunneling in soft ground Standing Peck. Proceedings of the 7th International Conference of Soil Mechanics and Foundation. State of the Art Volume.

4. O'reilly M P., New B M., (1982) Settlements above tunnels in the United Kingdom - their magnitude and prediction. Institution of Mining and Metallurgy.

5. Zhang B., Ma XM., Ren XF., Sun JX., (2014) Study on temporal and spatial distribution model of ground settlement caused by underground excavation of subway. Railway Engineering.

6. Sun Q., (2011) Analysis of soil displacement caused by tunnel excavation and its influence on adjacent pile foundation. Tongji University.

7. Li Z., (2014) Study on surface settlement of Kunming Metro Line 3 tunnel construction. Jilin University. 